\title{
HAEMANGIOMA OF THE ORBIT*
}

\section{CASE CAUSING PERIODIC VENOUS OBSTRUCTION AND EXOPHTHALMOS TREATED SUCCESSFULLY BY A POSTERIORLY PLACED ORBITAL DECOMPRESSION}

\author{
BY \\ G. F. ROWBOTHAM AND E. LITTLE \\ From the Department of Surgery, University of Newcastle upon Tyne
}

HAEMANGIOMAS are well-known formations; they occur all over the body although they are exceedingly rare in the orbit.

It is not our intention here to discuss the pathology of these neoplasms or malformations, as this has already been done adequately by Ewing (1940), Boyd (1947), and Willis (1948). For a comprehensive bibliography on orbital tumours and, in particular, on orbital haemangiomas, reference should be made to Reese's (1963) textbook Tumors of the Eye.

Our object in reporting this case is to illustrate certain special features of these formations. Also, we have had the opportunity of observing the clinical behaviour of this particular patient over a period of eighteen years. A specially designed posteriorly placed decompression was carried out to overcome venous obstruction at the sphenoidal fissure.

\section{Case Report}

A young woman aged 21 years, a dancer by profession, first came under our care in January, 1946. At that time she was complaining of drooping and swelling of the right upper eyelid and she was seeking treatment because her theatrical producer had come to the conclusion that this condition was disfiguring and, indeed, was incapacitating her for her career.

At the first examination a mild degree of exophthalmos was found and slight ptosis and swelling of the upper eyelid. The movements of the eyeball were restricted to a slight degree in all directions, but not sufficient to cause diplopia. The patient gave the important information that she had had periodic attacks in which the eyeball was pushed forwards and the eyelids became so swollen that she could not open them. At this stage it was suspected that she might have an intra-orbital vascular tumour, but no thrill or pulsation could be elicited. Vision was unimpaired and the retina was normal. The radiographs of the orbit and skull were normal. There was no disease elsewhere in the body and, in particular, no birthmarks were found in the skin.

At this stage it was felt that no further investigations were indicated and that it would be safest to wait for a period to see what happened.

In fact, the patient returned to the clinic a few days later when the orbital condition had worsened. The clinical picture was alarming. The eye was pushed forwards, the eyelid was swollen like a red

\footnotetext{
* Received for publication December 23, 1964.
} 

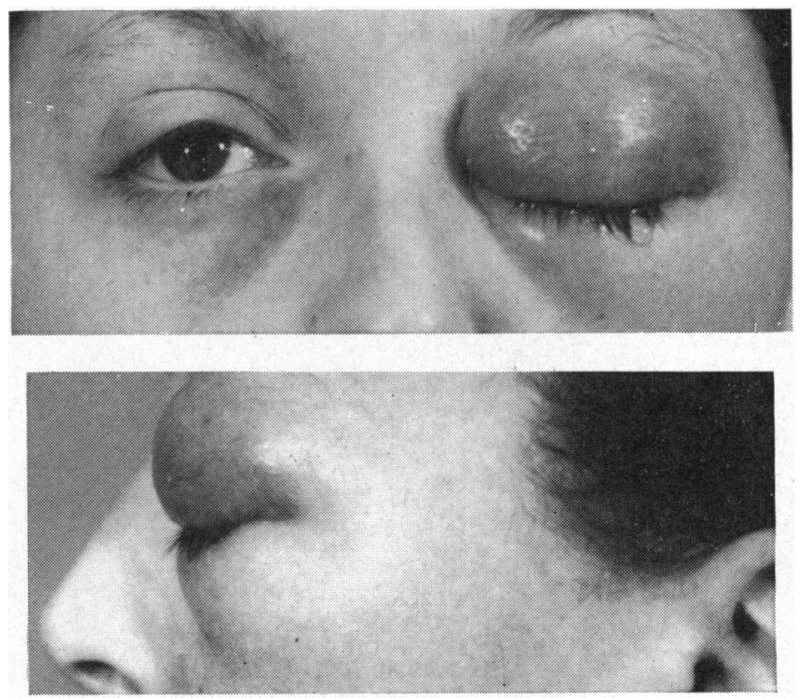

FIG. 1.-Condition before operation.

balloon, and the conjunctiva protruded in large oedematous folds (Fig. 1). The patient was admitted to hospital, and in spite of rest and local applications of cold compresses the eyeball remained proptosed and the eyelid swollen.

In order to try and confirm the clinical diagnosis of a haemangioma, an angiogram on that side was carried out by the percutaneous method. An injection of radio-opaque dye was made into the external carotid artery. The resulting radiograph showed an indeterminate shadow in the orbit, which at that time we were not able to interpret with any certainty. However, we believe that this was one of the first occasions in which external carotid angiography was used for the diagnosis of an orbital tumour.

Operation (January 24, 1946).-By a lateral approach to the orbit designed by one of us (Rowbotham, Clarke, and Hammersley, 1955), the thin bone of the roof and lateral wall of the orbital capsule were removed. Immediately the intra-orbital contents bulged and a heaving mass began to protrude. On palpation a distinct throb and thrill could be felt. Very soon it became obvious that we were dealing with a haemangioma and for this reason a biopsy specimen was not taken, nor was an excision attempted because the condition was not localized. Knowing that we were dealing with venous obstruction as well as mass formation, it was decided to remove the upper rim of the sphenoidal fissure. This was done subperiosteally so as to avoid damage to nerves and the attachments of the extra-ocular muscles-a manœuvre which was carried out successfully as the subsequent history will show.

Post-operative Progress. - The next day the condition was obviously subsiding and in three days the exophthalmos had disappeared, the oedema of the conjunctiva had receded, and the eyelid was normal. Within a few weeks the eye movements were free and full, as were the movements of the upper eyelid. This young lady was able to return to the stage and carry on her career for many years, and has never had an attack from that day to this (Fig. 2).

\section{Discussion}

In the very early stages the main differential diagnosis lay between a haemangioma and orbital cellulitis. One of the important features of this case was the long history suggesting very strongly that this particular haemangioma was a malformation rather than a neoplasm. The mechanism causing the tensions and swelling in this particular 

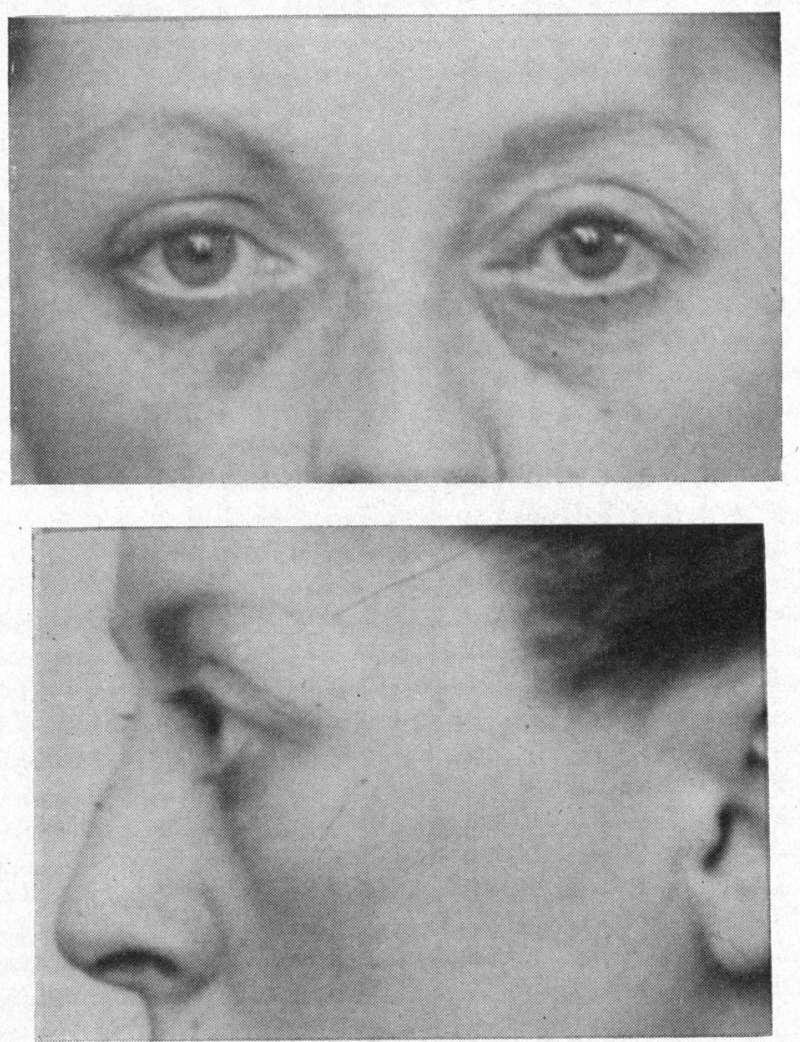

FIG. 2.-Condition after operation.

instance was venous obstruction at the sphenoidal fissure. It is unlikely that a simple orbital decompression without uncapping of the sphenoidal rim would have been successful in relieving the orbital tension and giving a long-lasting result. We would like to call attention again to our early efforts to make a diagnosis by external carotid angiography. Finally, it might be interesting to record that this case was closely followed in its early stages by the late Prof. H. M. Traquair.

\section{REFERENCES}

Boyd, W. (1947). "AA Text-book of Pathology", 5th ed., ch. 10. Henry Kimpton, London.

EwING, J. (1940). "Neoplastic Diseases", 4th ed., ch. 16. Saunders, Philadelphia.

REESE, A. B. (1963). "Tumors of the Eye", 2nd ed. Hoeber, New York.

Rowbotham, G. F., Clarke, P. R. R., and Hammersley, D. P. (1955). Brit. J. Surg., $42,524$.

Willis, R. A. (1948). "Pathology of Tumours", ch. 45. Butterworth, London. 